\title{
IMPROVEMENT OF CARDIOVASCULAR RISK FACTORS AND COSMETIC SIDE EFFECTS IN KIDNEY TRANSPLANT RECIPIENTS AFTER CONVERSION TO TACROLIMUS
}

\author{
Josef Zadrazila*, Pavel Horak ${ }^{\mathrm{a}}$, Jana Zahalkova ${ }^{\mathrm{a}}$, Pavel Strebla, Vladko Horcicka ${ }^{\text {a }}$, \\ Karel Krejci ${ }^{\mathrm{a}}$, Petr Bachleda ${ }^{\mathrm{b}}$, Jarmila Dedochova ${ }^{\mathrm{c}}$ and Ivo Valkovsky ${ }^{\mathrm{c}}$
}

\author{
a Department of Internal Medicine III, University Hospital, I. P. Pavlova 6, 77520 Olomouc, Czech Republic \\ ${ }^{b}$ Department of Surgery II, University Hospital, I. P. Pavlova 6, 77520 Olomouc, Czech Republic \\ c Department of Internal Medicine, Teaching Hospital, 17. listopadu 1790, 70852 Ostrava - Poruba, Czech Republic \\ e-mail:josef.zadrazil@fnol.cz
}

Received: June 16, 2008; Accepted: September 17, 2008

Key words: Renal transplantation/Cardiovascular mortality/Hypertension/Hyperlipidemia/Side effects/Cyclosporine/ Tacrolimus

Aims: Tacrolimus and Cyclosporine A (CyA) are cornerstones in immunosuppressive therapy. Cyclosporine side effects include hypertension and hypercholesterolemia both of which may increase the risk of cardiovascular mortality, gingival hyperplasia and hirsutism are known to reduce quality of life. The aim of this prospective study was to evaluate changes in cardiovascular risk profile and cosmetic side effects after conversion from CyA to tacrolimus.

Methods: 25 stable kidney transplant recipients ( 9 male, 16 female) were converted from a CyA to a tacrolimus based regimen. Mean age was $45.7 \pm 13.5$ years. Time to switch following transplantation was $4.7 \pm 1.7$ years. Reasons for conversion were multiple: arterial hypertension (9), hypertrichosis (3), gingival hyperplasia (3), hyperlipidemia (14).

Results: 19/25 patients completed the one year study period. One patient died, two returned to hemodialysis, two were switched back to CyA and one patient was lost to follow-up. There were statistically significant changes $(p=$ $<0.05$ ) in systolic and diastolic pressure and antihypertensive medication could be reduced in 13 patients. The dose of lipid-lowering agents could be reduced in the majority of the recipients and a complete withdrawal was achieved in 7 patients. Hypertrichosis and gingival hyperplasia resolved in all patients. Further, there was a significant improvement $(\mathrm{p}=<0.05)$ in urea and serum creatinine levels. Adverse events were consistent with the established safety profile for tacrolimus.

Conclusions: Conversion to a tacrolimus-based regimen led to an improvement in the cardiovascular risk profile. Further, cosmetic side effects which may lead to non-compliance, resolved after the switch.

\section{INTRODUCTION}

Cyclosporine and tacrolimus are calcineurin inhibitors, which are fundamental for currently used immunosuppressive protocol after transplantation. Cyclosporine and tacrolimus are effective in reducing the incidence of acute rejection. Both drugs have a similar safety profile but they differ with regards to the mechanism of action, safety profile, toxicities and side effects ${ }^{1,2}$.

Well-known side effects of CyA therapy are nephrotoxicity, arterial hypertension, hyperlipidemia, gingival hyperplasia and hypertrichosis ${ }^{3}$. Hyperlipidemic and hypertensive effects of CyA increase the risk of posttransplant cardiovascular disease and as important nontraditional risk factors contribute to the high cardiovascular morbidity and mortality in renal transplant patients ${ }^{4}$. Hyperlipidemia and hypertension are also risk factors for chronic transplant nephropathy and reduce long term graft function and survival ${ }^{5,6}$. Gingival hyperplasia and hypertrichosis are known to reduce quality of life and may lead to non-compliance ${ }^{7}$.

The above mentioned negative side effects associated with CyA can be substantially reduced by switching to tacrolimus based therapy. Results from previous studies suggest that tacrolimus is associated with less hypertension and hyperlipidemia ${ }^{8,9}$. Following conversion to tacrolimus also excellent results have been described in the resolution of gingival hyperplasia and hypertrichosis ${ }^{10}$.

The aim of this 12 months, open, prospective, single arm, one-centre study was to evaluate the efficacy and safety of the conversion from a CyA- to a tacrolimus-based immunosuppressive regimen in a group of stable kidney transplant patients suffering from CyA related side effects.

\section{PATIENTS AND METHODS}

This was a prospective, nonrandomized, single - arm, one - center study which was conducted according to ICH/GCP guidelines in the University Hospital Olomouc. The trial was approved by the Local Ethics Committee and all patients gave written and dated informed consent before inclusion in the study. The endpoints of this study were to evaluate the impact of tacrolimus on cardiovascular risk factors, graft function and cosmetic side effects 
Table l. Evolution of blood pressure and urea and creatinine serum concentration.

\begin{tabular}{|l|c|c|c|c|c|c|c|c|}
\hline \multirow{2}{*}{ Time } & \multicolumn{2}{|c|}{$\begin{array}{c}\text { Systolic BP } \\
(\mathrm{mm} \mathrm{Hg})\end{array}$} & \multicolumn{2}{c|}{$\begin{array}{c}\text { Diastolic BP } \\
(\mathrm{mm} \mathrm{Hg})\end{array}$} & \multicolumn{2}{c|}{$\begin{array}{c}\text { Urea } \\
(\mathrm{mmol} / 1)\end{array}$} & \multicolumn{2}{c|}{$\begin{array}{c}\text { Creatinine } \\
(\mu \mathrm{mol} / \mathrm{l})\end{array}$} \\
\cline { 2 - 9 } & Mean & SD & Mean & SD & Mean & SD & Mean & SD \\
\hline Day 0 & 142.0 & 21.4 & 84.0 & 9.0 & 11.48 & 5.86 & 184.4 & 80.1 \\
\hline Week 1 & 134.0 & 14.5 & 81.1 & 7.9 & 12.89 & 6.12 & 185.1 & 69.9 \\
\hline Week 2 & 133.7 & 18.3 & 81.1 & 8.3 & 12.08 & 4.80 & 204.2 & 93.4 \\
\hline Month 1 & 134.7 & 20.5 & 82.1 & 8.1 & 12.32 & 9.63 & 194.0 & 94.7 \\
\hline Month 2 & 134.6 & 14.7 & 80.1 & 8.4 & 10.72 & 5.75 & 180.7 & 81.5 \\
\hline Month 3 & 137.6 & 11.0 & 82.9 & 8.6 & 11.66 & 8.22 & 187.2 & 90.9 \\
\hline Month 4 & 134.5 & 16.4 & 82.1 & 8.5 & 10.92 & 5.67 & 179.7 & 81.2 \\
\hline Month 5 & 134.0 & 11.0 & 81.1 & 7.9 & 11.15 & 4.53 & 184.4 & 73.9 \\
\hline Month 6 & 133.6 & 15.3 & 81.1 & 8.1 & 10.17 & 6.00 & 177.8 & 75.6 \\
\hline Month 7 & 131.8 & 11.8 & 80.1 & 9.0 & 11.24 & 5.77 & 175.7 & 86.9 \\
\hline Month 8 & 127.1 & 13.1 & 80.1 & 8.8 & 10.87 & 5.80 & 173.7 & 91.3 \\
\hline Month 9 & 132.1 & 16.5 & 79.2 & 7.9 & 11.18 & 6.68 & 175.5 & 92.8 \\
\hline Month 10 & 130.5 & 12.7 & 79.2 & 7.6 & 10.53 & 5.54 & 178.7 & 88.3 \\
\hline Month 11 & 125.6 & 13.4 & 80.2 & 7.8 & 11.56 & 6.24 & 164.3 & 70.3 \\
\hline Year 1 & 129.2 & 13.9 & 81.2 & 7.7 & 10.25 & 5.18 & 164.8 & 70.8 \\
\hline
\end{tabular}

Table 2. Evolution of parameters of lipid metabolism.

\begin{tabular}{|l|c|c|c|c|c|c|c|c|}
\hline \multirow{2}{*}{ Time } & \multicolumn{2}{|c|}{$\begin{array}{c}\text { Cholesterol } \\
(\mathrm{mmol} / 1)\end{array}$} & \multicolumn{2}{c|}{$\begin{array}{c}\text { Triglycerides } \\
(\mathrm{mmol} / \mathrm{l})\end{array}$} & \multicolumn{2}{c|}{$\begin{array}{c}\text { LDL cholesterol } \\
(\mathrm{mmol} / \mathrm{l})\end{array}$} & \multicolumn{2}{c|}{$\begin{array}{c}\text { HDL cholesterol } \\
\text { (mmol/1) }\end{array}$} \\
\cline { 2 - 9 } & Mean & SD & Mean & SD & Mean & SD & Mean & SD \\
\hline Day 0 & 5.61 & 1.19 & 2.27 & 1.39 & 2.94 & 0.96 & 1.39 & 0.47 \\
\hline Week 1 & 5.10 & 1.23 & 1.98 & 1.11 & 3.51 & 0.98 & 1.40 & 0.42 \\
\hline Week 2 & 5.36 & 1.13 & 2.08 & 1.23 & 2.71 & 0.86 & 1.43 & 0.47 \\
\hline Month 1 & 4.79 & 0.91 & 1.80 & 0.88 & 2.71 & 0.87 & 1.09 & 0.40 \\
\hline Month 2 & 4.75 & 0.81 & 2.01 & 1.12 & 2.50 & 0.94 & 1.31 & 0.46 \\
\hline Month 3 & 4.91 & 0.76 & 1.81 & 1.01 & 2.45 & 0.73 & 1.55 & 0.55 \\
\hline Month 4 & 5.44 & 1.29 & 2.15 & 1.30 & 3.01 & 0.86 & 1.10 & 0.53 \\
\hline Month 5 & 5.22 & 1.30 & 1.97 & 1.08 & 2.74 & 0.98 & 1.39 & 0.48 \\
\hline Month 6 & 5.31 & 1.20 & 2.15 & 1.08 & 2.71 & 0.85 & 1.50 & 0.54 \\
\hline Month 7 & 5.31 & 1.20 & 1.99 & 0.95 & 2.52 & 0.89 & 1.29 & 0.53 \\
\hline Month 8 & 5.05 & 0.98 & 2.06 & 0.83 & 3.43 & 0.65 & 1.12 & 0.47 \\
\hline Month 9 & 5.05 & 0.96 & 2.03 & 0.90 & 2.58 & 0.83 & 1.50 & 0.41 \\
\hline Month 10 & 5.11 & 1.05 & 2.20 & 1.00 & 2.71 & 0.71 & 1.12 & 0.42 \\
\hline Month 11 & 4.92 & 1.02 & 2.06 & 0.96 & 2.76 & 0.79 & 0.96 & 0.51 \\
\hline Year 1 & 4.68 & 0.97 & 2.13 & 0.97 & 2.49 & 0.68 & 1.40 & 0.52 \\
\hline
\end{tabular}

in kidney transplant recipients following conversion from cyclosporine.

Subjects who met all of the following inclusion criteria were eligible for this study:

Male or female patients, 18 years or older, patients with hyperlipidemia defined as fasting total cholesterol concentration in serum above $6.5 \mathrm{mmol} / 1$ or triglycerides serum concentration above $2.5 \mathrm{mmol} / 1$, patients with arterial hypertension, systolic blood pressure $\geq 140 \mathrm{~mm} \mathrm{Hg}$ or diastolic blood pressure $\geq 90 \mathrm{~mm} \mathrm{Hg}$ despite treatment with at least one antihypertensive drug, gingival hyperplasia, hypertrichosis severe enough to require treatment, primary kidney transplantation or re-transplantation from a deceased donor and female patients of child bearing age who agreed to maintain effective birth control practice during the study.

Exclusion criteria included: Female patients who were pregnant or breast feeding, patients $<18$ years of age, allergy or intolerance to HCO-60 or structurally related compounds, macrolide antibiotics or tacrolimus, patients required ongoing systemic immunosuppressive therapy other than for kidney transplantation, patients with present malignant disease, patients with significant, uncontrolled concomitant infections and/or severe diarrhea, vomiting or active peptic ulcer, and patients participating in another clinical trial. 
Before conversion the patients were treated with the well -established triple-drug maintenance immunosuppressive regimen consisting of CyA (Sandimmun Neoral) combined with mycophenolate mofetil (CellCept) and corticosteroids (Prednison). The doses of Sandimmun Neoral in these long-term transplant patients were adjusted to maintain target whole blood trough levels between 100-200 ng/ml. Cyclosporine levels were measured using FPIA (Fluorescence polarisation immunoassay), Abbott diagnostics. Doses of CellCept and Prednison were $20 \mathrm{mg} / / \mathrm{kg} /$ day and $5 \mathrm{mg} /$ day respectively.

Mean time to switch following transplantation was $4.7 \pm 1.7$ years. Tacrolimus (Prograf) was started within 24 hours after patients received last dose of CyA. Initial daily dose of Prograf after switching was $0.1 \mathrm{mg} / \mathrm{kg} /$ day, divided into two doses. Target tacrolimus blood trough levels were $5-15 \mathrm{ng} / \mathrm{ml}$ at months 1 and $4-10 \mathrm{ng} / \mathrm{ml}$ by month 6. Tacrolimus levels were measured using MEIA (Microparticle enzyme immunoassay), Abbott diagnostics. No changes were made in concomitant immunosuppressive therapy after switch to tacrolimus.

Clinical status (physical examination, body weight, blood pressure, cosmetic side effects) and laboratory parameters (serum creatinine, plasma urea, aspartate aminotransferase-AST, alanine aminotrasferase-ALT, serum bilirubin, glycaemia, triglycerides, total cholesterol, high density lipoprotein cholesterol-HDL cholesterol, low density lipoprotein cholesterol-LDL cholesterol) were monitored weekly for the first month after conversion and monthly thereafter. Blood pressure was measured in a sitting position after at least 5 minutes rest by certificated automated equipment. Blood samples for laboratory assessments were taken after overnight fasting and were measured at a certified routine clinical chemistry laboratory on the Hitachi 917 analyzer (Roche).

All statistical analyses were performed by the linear regression analysis using data software system ADSTAT version 2.0 and QC EXPERT version 2.7.

\section{RESULTS}

Twenty five renal transplant recipients were converted to a tacrolimus - based regimen, 9 male (36\%), 16 female (64\%). The mean age was $45.7 \pm 13.5$ years (range $23-59$ ). The causes of end-stage renal disease prior transplantation in the study population were chronic glomerulonephritis $(\mathrm{n}=10 ; 40 \%)$, chronic tubulointerstitial nephritis $(\mathrm{n}=$ $7 ; 28 \%)$, diabetic nephropathy $(n=4 ; 16 \%)$, autosomal dominant polycystic kidney disease $(n=3 ; 12 \%)$ and Alport's syndrome $(n=1 ; 4 \%)$. No patients had active virus $\mathrm{B}$ or $\mathrm{C}$ hepatitis.

Nineteen patients completed the one year study period. One patient died from acute myocardial infarction. Two patients had a substantially elevated serum creatinine levels at study entry and they had to go back to dialysis due to graft failure. Two patients were switched back to cyclosporine: One patient under tacrolimus treatment had diarrhoea and the second one decided to quit the medication as mild alopecia occurred. One patient was lost to follow-up. The available data of all 25 patients are summarized in Table 1 and Table 2.

Mean systolic blood pressure was reduced from $142.0 \pm 21.4 \mathrm{~mm} \mathrm{Hg}$ at baseline to $129.2 \pm 13.9 \mathrm{~mm} \mathrm{Hg}$ at week 52 (Fig. 1; regression curve $\mathrm{y}=138-0.719 \mathrm{x}$ ). Mean diastolic blood pressure was reduced from $84.0 \pm 9.0 \mathrm{~mm}$ $\mathrm{Hg}$ at baseline to $81.2 \pm 7.7 \mathrm{~mm} \mathrm{Hg}$ at the end of one year observation (Fig. 2; regression curve $y=82.53-0.2 x$ ). Observed changes in systolic and diastolic blood pressure were statistically significant $(\mathrm{p}<0.05)$ and antihypertensive medication could be reduced in 13 patients.

No nephrotoxicity or acute rejection episodes were observed after conversion to tacrolimus. Mean serum urea concentration decreased from $11.48 \pm 5.86 \mathrm{mmol} / \mathrm{l}$ at baseline to $10.25 \pm 5.18 \mathrm{mmol} / 1$ at week 52 (Fig. 3; regression curve $\mathrm{y}=12.126-0.107 \mathrm{x}$ ) and mean serum creatinine decreased from $184.4 \pm 80.1 \mu \mathrm{mol} / 1$ to $164.8 \pm 70.8 \mu \mathrm{mol} / 1$ at week 52. (Fig. 4; regression curve $\mathrm{y}=195.2-1.81 \mathrm{x}$ ). The improvement in urea and serum creatinine levels was statistically significant $(\mathrm{p}<0.05)$.

Mean serum total cholesterol level at baseline was 5.61 \pm 1.19 and after conversion at week 52 was $4.68 \pm 0.97$ $\mathrm{mmol} / 1$ (Fig. 5; regression curve $\mathrm{y}=5.285-0.022 \mathrm{x}$ ). Mean serum triglycerides levels before conversion was $2.27 \pm$ $1.39 \mathrm{mmol} / \mathrm{l}$ and after switch to tacrolimus at week 52 was $2.13 \pm 0.97$ (Fig. 6; regression curve $\mathrm{y}=2.000-0.005 \mathrm{x}$ ). Mean LDL cholesterol level at baseline was $2.94 \pm 0.96$ $\mathrm{mmol} / 1$ and at week 52 after switch $2.49 \pm 0.68 \mathrm{mmol} / 1$ (Fig. 7; regression curve $y=2.94-0.02 x$ ). Mean HDL cholesterol concentration was at the start of the study $1.39 \pm$ $0.47 \mathrm{mmol} / 1$ and at the end of study $1.40 \pm 0.52 \mathrm{mmol} / 1$ (Fig. 8; regression curve $y=1.397-0.012 \mathrm{x}$ ). With the exception of HDL there was a trend towards lower values for these parameters however the differences did not reach statistical significance. It is noteworthy that the dose of lipid-lowering agents could be reduced in the majority of the recipients and a complete withdrawal was achieved in 7 patients ( $50 \%$ of hyperlipidemic patients).

Hypertrichosis and gingival hyperplasia resolved in all patients. No new onset or worsening of diabetes mellitus was observed after conversion. There were no significant changes in fasting blood glucose concentrations during the study $(5.56 \pm 1.11$ vs. $5.69 \pm 1.00 \mathrm{mmol} / 1)$. No changes in liver function parameters were observed. Adverse events were consistent with the established safety profile for tacrolimus.

\section{DISCUSSION}

Cyclosporine together with tacrolimus represent a group of calcineurin inhibitors which have the ability to inhibit calcineurin phosphatase, the essential enzyme in the process of the gene transcription for interleukin-2 (IL2) and other proinflammatory cytokines. The inhibition of calcineurin phosphatase results mainly in suppression of $\mathrm{T}$ cell activation but it also suppresses molecules involved in cell-mediated immunity. The consequence of 


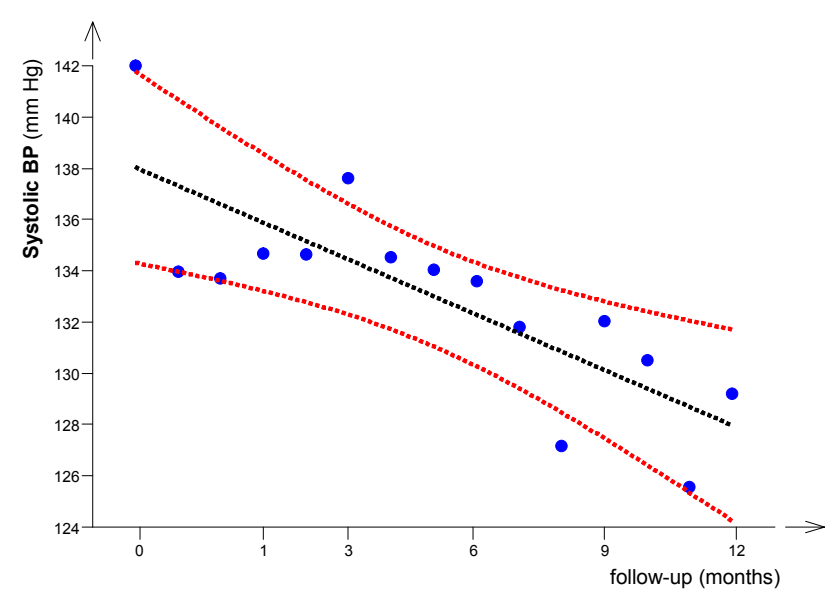

Fig. 1. Changes in systolic blood pressure.

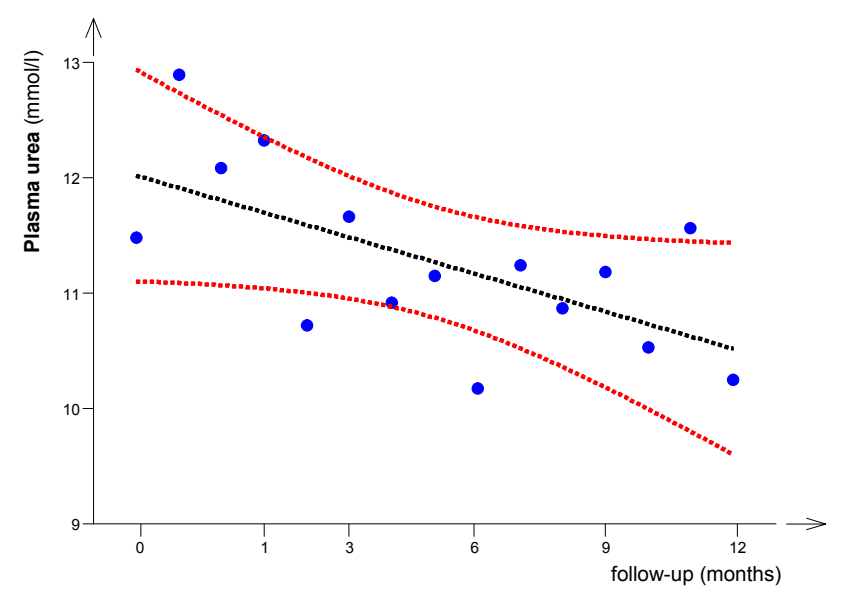

Fig. 3. Changes in serum creatinine level.

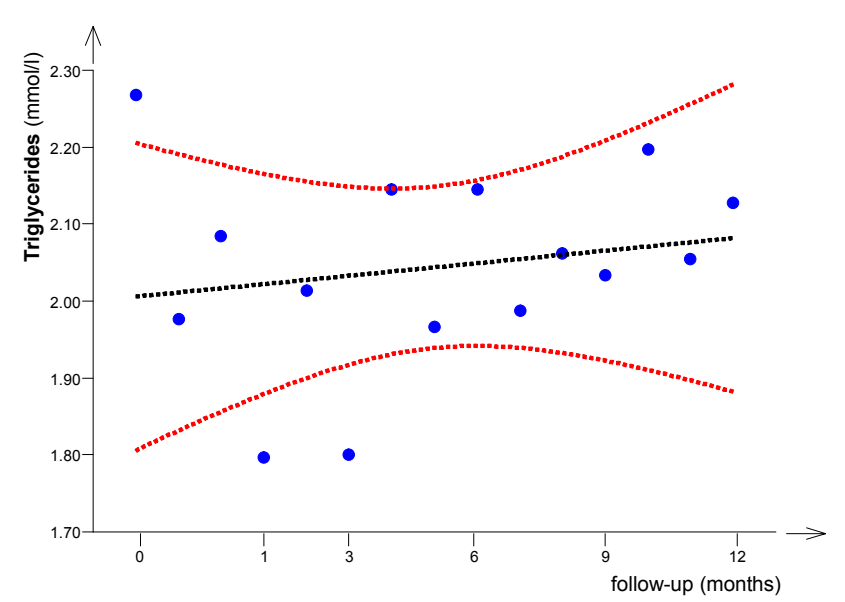

Fig. 5. Changes in serum tiglycerides.

this is interruption in the downstream sequence of events leading to allograft rejection. Despide this fact, there are many differences in action, safety profile, toxicities and side effect between these two drugs ${ }^{2,3,11}$.

Tacrolimus, in comparison with CyA significantly reduces the incidence of acute rejection and improves survival of grafts as well as patients after kidney trans-

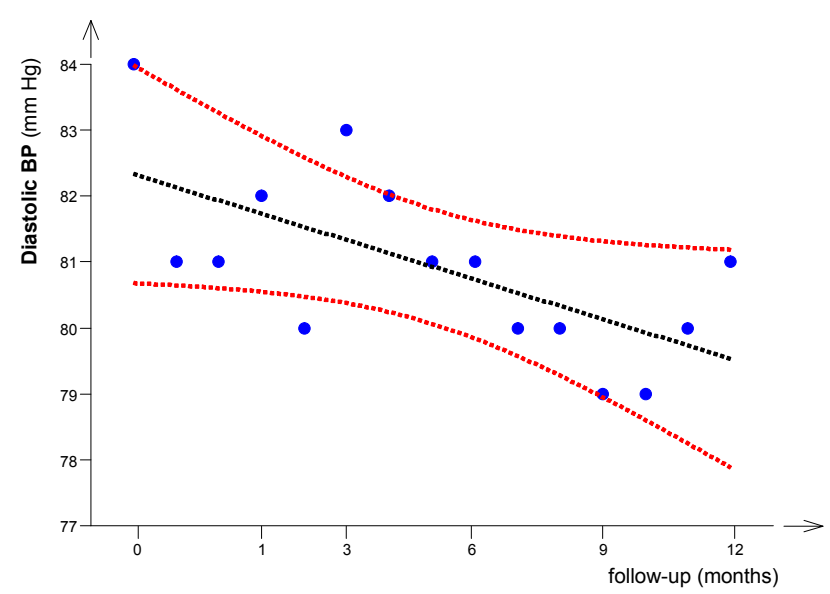

Fig. 2. Changes in diastolic blood pressure.

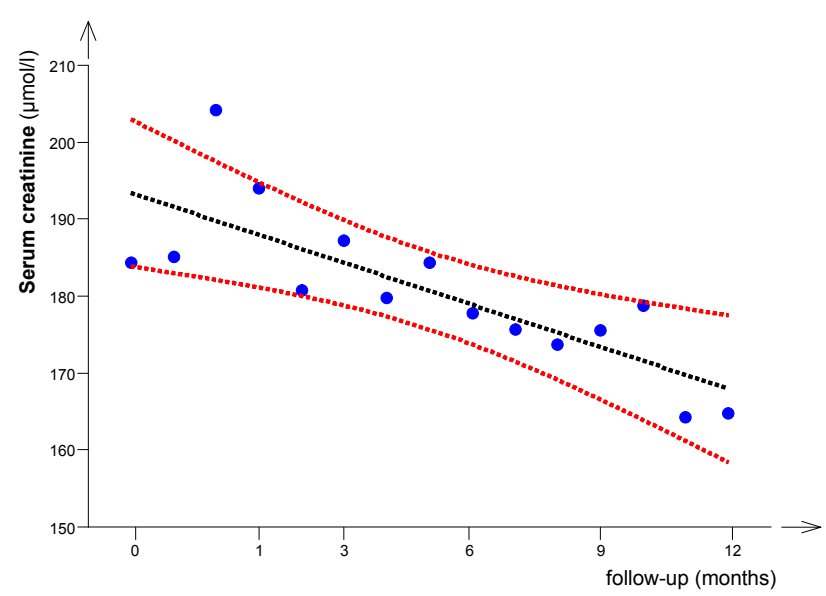

Fig. 4. Changes in plasma urea level.

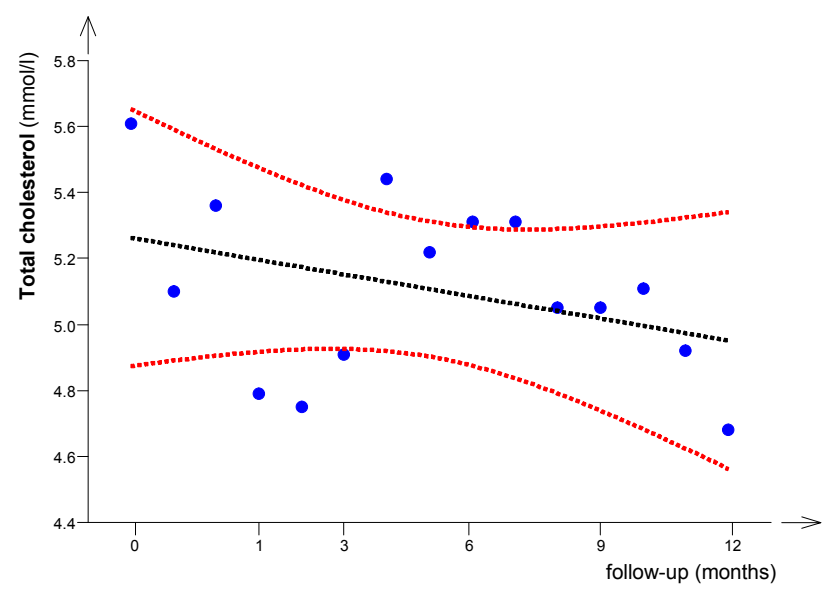

Fig. 6. Changes in serum total cholesterol.

plantation $^{12}$. Long term monitoring of the result of the tacrolimus and CyA therapy has confirmed, that tacrolimus-based immunosuppressive therapy significantly reduces the risk of graft failure. According to the results of an American multicenter, comparative, randomized study the five-year graft survival rate in the tacrolimus arm was $63.8 \%$, whereas in the CyA arm only $53.8 \%$. The differ- 


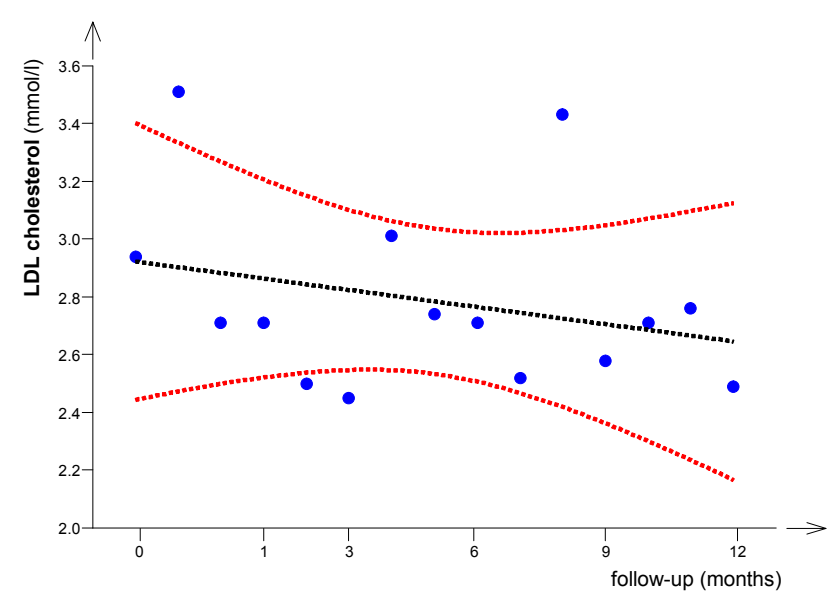

Fig. 7. Changes in serum LDL cholesterol.

ence in the patients' survival rate in both groups, however, did not reach statistical significance ${ }^{13}$.

Development of molecular-biological technique helps clarify the cause of the better immunosuppressive effectiveness of tacrolimus in comparison with CyA. A most important finding of immunological research and related to this, is that tacrolimus, unlike CyA, lowers mRNA expression for IL-10, increases apoptosis of T lymphocytes activated by anti-gene, decreases production of antibody against HLA as well as HLA anti genes and significantly decreases proliferation of vas intima ${ }^{1,14,15}$.

From the long-term point of view, particularly significant is the fact, that tacrolimus, unlike CyA, has no effects on levels of transforming $\beta$ factor (TGF $\beta$ ), which has an important fibroproductive potential and is considered the key factor in the development of chronic transplant nephropathy and cosmetic side effects ${ }^{16,17}$.

Nonimmunological factors that are very important for graft and patient survival are hyperlipidemia and arterial hypertension. Hypertension after calcineurin inhibitors is caused by renal vasoconstriction and sodium retention. Long term CyA treatment in renal transplant patient resulted in higher renal vascular resistance and greater need for antihypertensive therapy compared with tacrolimus ${ }^{18}$. Hypertension and hyperlipidemia are common complications after renal transplantation and both are not only important determinants of graft function and graft survival, but also very important cardiovascular risk factors in the transplanted population. In general patients after kidney transplantation are at high risk of developing cardiovascular disease. Patients treated with CyA tend to have higher blood pressure, higher total cholesterol and LDL cholesterol levels and cosmetic adverse events - gingival overgrowth and hypertrichosis ${ }^{12}$. Tacrolimus is less nephrotoxic than CyA and has a more favourable cardiovascular risk profile due to better graft function and better lipid and blood pressure profile compared to $\mathrm{CyA}^{4}$. However, the incidence of glucose intolerance and postransplant diabetes mellitus is higher in tacrolimus treated patients ${ }^{19}$.

The results of our one-year study demonstrated, that

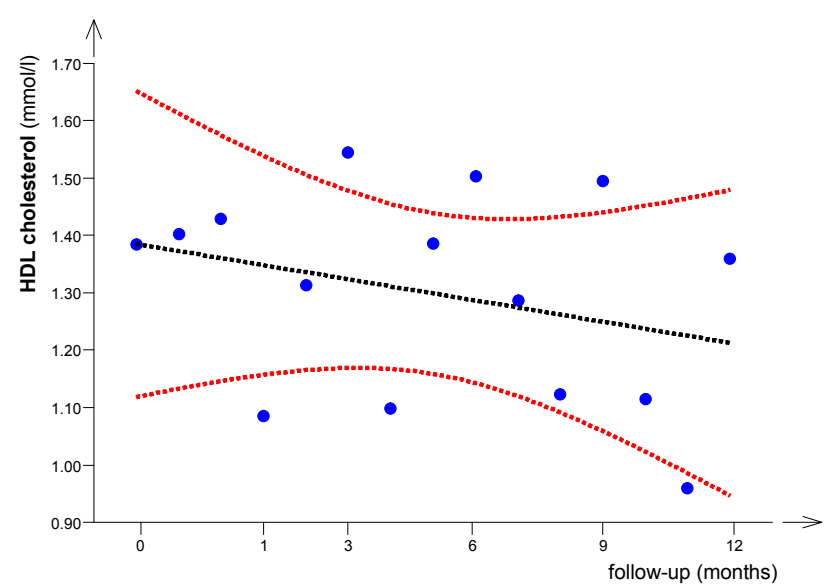

Fig. 8. Changes in serum HDL cholesterol.

following conversion from a CyA to a tacrolimus based immunosuppression protocol systolic and diastolic blood pressure were statistically significant decreased and antihypertensive medication could be reduced in 13 patients. The dose of lipid lowering agents could be reduced in the majority of the recipients and complete withdrawal was achieved in 7 patients ( $50 \%$ of hyperlipidemic patients). Furthermore graft function improved, with a statistically significant decrease in mean serum urea concentration and mean serum creatinine concentration. Hypertrichosis and gingival hyperplasia resolved in all patients.

In some aspects similar observations concerning the cardiovascular risk factors after renal transplantation and side effects of cyclosporine have been published in several other studies. In the European Tacrolimus vs. Cyclosporine Microemulsion Renal Transplant Study Group the authors found significant lower cholesterol levels and mean arterial blood pressure in tacrolimus treated patients. The summary measure of serum triglycerides was not different between treatment groups ${ }^{20}$. The better cardiovascular risk profile of tacrolimus based immunosuppression was confirmed in a 2 years follow-up of this study. Graft loss, patient death and biopsy-proven acute rejection occurred significantly more frequently in patients treated with cyclosporin than in the tacrolimus arm. Graft function at 2 years post-transplantation was significantly better and cholesterol and triglycerides concentrations were lower in the tacrolimus arm compared to the cyclosporine arm ${ }^{21}$. In the European Switch to Tacrolimus Study 296 adult kidney transplant patients with cyclosporine related side effects were converted to tacrolimus. Tacrolimus was well tolerated and the study demonstrated a substantial reduction in cardiovascular risk factors especially hyperlipidemia and arterial hypertension following the switch to tacrolimus-based therapy ${ }^{22}$.

In a 6 months randomised controlled conversion study of 124 renal transplant recipients published by M. Artz et al a significant decrease in blood pressure, LDL cholesterol, serum apolipoprotein B and serum triglycerides was observed after conversion. Furthermore renal function improved $^{23}$. A follow-up of 2 years in this study demon- 
strated that conversion from cyclosporine to tacrolimus was beneficial to renal function, cardiovascular risk profile and side effects. The Framingham risk score decreased from $5.7 \pm 4.3$ to $4.8 \pm 5.3$ (ref. $^{24}$ ).

A significant reduction in systolic blood pressure, serum total cholesterol, LDL cholesterol, HDL cholesterol and triglycerides after conversion to tacrolimus were seen in a six months study published by Marcén ${ }^{25}$. No changes in diastolic blood pressure were observed in this study. In contrast to this, in an open-label single-arm prospective study in 22 adult renal recipients converted from cyclosporine to tacrolimus, significant improvement in fibrinogen, total cholesterol and LDL cholesterol levels was observed but there were no significant differences in HDL cholesterol, homocystein, C-reactive protein, haemoglobin A1c levels, serum creatinine, mean blood pressure and mean number of antihypertensive medication before and after conversion ${ }^{26}$.

Finally, in a one-year observation study of kidney allograft recipients converted from cyclosporine microemulsion to tacrolimus no changes in mean systolic and diastolic blood pressure were observed but significant changes in creatinine levels, total cholesterol levels and LDL cholesterol levels were described ${ }^{27}$.

Well-known side effects of CyA treatment are hypertrichosis and gingival hypertrophy ${ }^{10}$. These complications may cause significant morbidity and have psychological impact in transplant patients. Gingival hyperplasia may be associated with gum bleeding, pain and tooth loss. Pathogenesis of CyA induced gingival overgrowth is multifactorial. The dosage of CyA, duration of therapy as well as plasmatic and salivary concentrations of CyA play a central role. In addition, many other factors such as standards of oral hygiene, age, genetic predisposition, gingival inflammation, some growth factors, especially TGF $\beta$ and synergic or protective effects of other prescribed drugs contribute to the development of gingival hyperplasia ${ }^{7,28}$.

Gingival hyperplasia and hypertrichosis usually regressed completely within several months after switch from CyA to tacrolimus in the majority of patients effected. Residual gingival hyperplasia may persist in some individuals but is generally asymptomatic and requires no further specific dental treatment ${ }^{7}$.

In our study gingival hyperplasia and hypertrichosis significantly or completely resolved in all patients converted to tacrolimus. The resolution of hypertrichosis and gingival hypertrophy improved body image, patient satisfaction and may lead not only to better quality of life, but also to better therapy compliance ${ }^{29,30}$.

\section{CONCLUSION}

The results of our study demonstrated, that conversion from CyA to tacrolimus in stable chronic transplant recipients was associated with significant decrease of systolic and diastolic blood pressure $(p<0.05)$. With respect to graft function urea and creatinine serum levels significantly decreased $(\mathrm{p}<0.05)$. Conversion from cyclosporine to tacrolimus further allowed reduction of lipid-lowering agents in the majority of the recipients and a complete withdrawal was achieved in 7 patients $(50 \%$ of hyperlipidemic patients). These findings confirmed better cardiovascular risk profile of tacrolimus based immunosuppression. Cosmetic side effects resolved after the switch, which may lead to better compliance and better quality of life.

\section{ACKNOWLEDGMENT}

Supported by the grant No. NS/9964-4 of the Internal Grant Agency, Ministry of Health, Czech Republic.

\section{REFERENCES}

1. Almawi WY, Melemedjian O. Clinical and mechanistic differences between FK 506 (tacrolimus) and cyclosporin A. Nephrol Dial Transplant 2000; 15: 1946-1978.

2. Tang IY, Meier-Kriesche HU, Kaplan B. Immunosuppressive strategies to improve outcomes of kidney transplantation. Semin Nephrol 2007; 4: 377-392.

3. Kahan BD. Ciclosporin. N Engl J Med 1989; 321: 1725-1738.

4. Ligtenberg G, Hene RJ, Blankestijn PJ, Koomans HA. Cardiovascular risk factors in renal transplant patients: cyclosporin A versus tacrolimus. J Am Soc Nephrol 2001; 12: 368-373.

5. Roodnat JI, Mulder PG, Zietse R, Rischen-Vos J, vanRiemsdijk IC, IJzermans JN et al. Cholesterol as an independent predictor of outcome after renal transplantation. Transplantation 2000; 69: 1704-1710.

6. Castelló IB. Hyperlipidemia: A risk factor for chronic allograft dysfunction. Kidney Int 2002; 61:73-77.

7. Busque S, Demers P, St-Louis G, Boily JG, Tousignant J, Lemieux $F$ et al. Conversion from Neoral (cyclosporine) to tacrolimus of kidney transplant recipients for gingival hyperplasia or hypertrichosis. Transplant Proc 1998; 30:1247-1248.

8. Friemann S, Feuring E, Padberg W, Ernst W. Improvement of nephrotoxicity, hypertension, and lipid metabolism after conversion of kidney transplant recipients from cyclosporine to tacrolimus. Transplatn Proc 1998; 30:1240-1242.

9. Copley JB, Staffeld C, Lindberg J, Hansen A, Bailey C, Anand R et al. Cyclosporin to tacrolimus: effect on hypertension and lipid profiles in renal allografts. Transplant Proc 1998; 30:1254-1256.

10. Fernando ON, Sweny P, Varghese Z. Elective conversion of patients from cyclosporine to tacrolimus for hypertrichosis. Transplant Proc 1998; 30:1243-1244.

11. Matsuda S, Koyasu S. Mechanism of action of cyclosporine. Immunopharmacology 2000; 47: 119-125.

12. Margreiter $\mathrm{R}$ for the European Tacrolimus vs Ciclosporin Microemulsion Renal Transplant Study Group. Efficacy and safety of tacrolimus compared with ciclosporin microemulsion in renal transplantation: A randomised multicentre study. Lancet 2002; 395: 741-746.

13. Vincenti F, Jensik SC, Filo RS, Miller J, Pirsch J. A long-term comparison of tacrolimus (FK-506) and cyclosporine in kidney transplantation: Evidence for improved allograft survival at five years. Transplantation 2002; 73:775-782.

14. Klein IHHT, Abrahams A, van Ede T, Hené RJ, Koomans HA, Ligtenberg G. Different effects of tacrolimus and cyclosporine on renal hemodynamics and blood pressure in healthy subjects. Transplantation 2002; 73: 732-736.

15. Jiang H, Wynn C, Pan F, Ebbs A, Erickson LM, Kobayashi M. Tacrolimus and cyclosporine differ in their capacity to overcome ongoing allograft rejection as a result of their differential abilities to inhibit interleukin-10 production. Transplantation 2002; 73: 18081817. 
16. Gaston RS. Maintenance Immunosuppression in the Renal Transplant Recipient: An Overview. Am J Kidney Dis 2001; 38 (Suppl 6): 25-35.

17. Chae HJ, Ha MS, Yun DH, Pae HO, Chung HT, Chae SW et al. Mechanism of Cyclosporine-induced overgrowth in Gingiva. J Dent Res 2006; 85: 515-519.

18. Radermacher J, Meiners M, Bramlage C, Kliem V, Behrend M, Schlitt HJ et al. Pronounced renal vasoconstriction and systemic hypertension in renal transplant patients treated with cyclosporine A versus FK 506. Transplant Int 1998;11: 3-10.

19. Kasiske BL, Snyder JJ, Gilbertson D, Matas AJ. Diabetes mellitus after kidney transplantation in the United States. Am J Transplant 2003; 3: 178-185.

20. Krämer BK, Zülke C, Kammerl MC, Schmidt C, Hengstenberg $\mathrm{C}$, Fischereder M et al. European Tacrolimus vs Cyclosporine Microemulsion Renal Transplantation Study Group: Cardiovascular risk factor and estimated risk for CAD in a randomized trial comparing calcineurin inhibitors in renal transplantation. Am J Transplant 2003; 8: 982-987.

21. Krämer BK, Montagnino G, Del Castillo D, Margreiter R, Sperschneider H, Olbricht CJ et al., European Tacrolimus vs Cyclosporin Microemulsion Renal Transplantation Study Group: Efficacy and safety of tacrolimus compared with cyclosporin A microemulsion in renal transplantation: 2 year follow-up results. Nephrol Dial Transplant 2005; 20: 968-973.

22. Margreiter R, Pohanka E, Sparacino V, Sperschneider H, Kunzendorf U, Huber W et al., the European Switch to Tacrolimus Study Group: Open prospective multicenter study of conversion to tacrolimus therapy in renal transplant patients experiencing ciclosporin-related side-effects. Transplant Int 2005; 18:816-823.
23. Artz MA, Boots JM, Ligtenberg G, Roodnat JI, Christiaans MH, Vos PF et al. Improved cardiovascular risk profile and renal function in renal transplant patients after randomized conversion from cyclosporine to tacrolimus. J Am Soc Nephrol 2003; 14:1880-1888.

24. Artz MA, Boots JM, Ligtenberg G, Roodnat JI, Christiaans $\mathrm{MH}, \mathrm{Vos} \mathrm{PF}$ et al. Conversion from Cyclosporine to Tacrolimus Improves Quality of-Life Indices, Renal Graft Function and Cardiovascular Risk Profile. Am J Transplant 2004; 4: 937-945.

25. Marcén R, Chahin J, Alarcón A, Bravo J. Conversion from cyclosporine microemulsion to tacrolimus in stable kidney transplant patients with hypercholesterolemia is related to an improvement in cardiovascular risk profile: a prospective study. Transplant Proc 2006; 38: 2427-2430.

26. Baid-Agrawal S, Delmonico FL, Tolkoff-Rubin NE, Farrell M, Williams WW, Shih A et al. Cardiovascular risk profile after conversion from cyclosporine A to tacrolimus in stable renal transplant recipients. Transplantation 2004; 77: 1199-1202.

27. Chamienia A, Biedunkiewicz B, Król E, Debska-Slizień A, Rutkowski B. One-year observation of kidney allograft recipients converted from cyclosporine microemulsion to tacrolimus. Transplant Proc 2006; 38:81-85.

28. Vescovi P, Meleti M, Manfredi M, Bonanini M. Pathogenesis of cyclosporine induced gingival overgrowth. Minerva Stomatol 2003; 52: 219-229.

29. Thorp M, DeMattos A, Bennett W, Barry J, Norman D. The effect of conversion from cyclosporine to tacrolimus on gingival hyperplasia, hirsutism and cholesterol. Transplantation 2000; 69: 1218-1220.

30. Kohnle M, Lütkes P, Zimmermann U, Philipp T, Heemann U. Conversion from cyclosporine to tacrolimus in renal transplant recipients with gum hyperplasia. Transplant Proc 1999; 31: 44S-45S. 
